\title{
BULLYING E COTIDIANO ESCOLAR: SENSIBILIZAÇÃO POR INTERMÉdio dA EdUCAÇÃo EM DiREITOS HuMANOS
}

\author{
BULLYING AND EVERYDAY SCHOOL: AWARENESS THROUGH HUMAN \\ RIGHTS EDUCATION
}

DOI: $\underline{\text { 10.23926/RPD.2526-2149.2020.v5.n2.p1477-1498.id805 }}$

\author{
Vanessa Costa \\ Gonçalves Silva \\ Mestre em Ensino \\ (IFMT/UNIC) \\ Instituto Federal de Mato \\ Grosso (IFMT) \\ vanessa.silva@blv.ifmt.edu.b \\ $\underline{\mathrm{r}}$
}

\section{Raquel Martins \\ Fernandes}

Pós-Doutorado em

Psicologia Social (UFPB)

Instituto Federal de Mato

Grosso (IFMT)

raquel.fernandes@blv.ifmt.e du.br

\begin{abstract}
Resumo: Este artigo tem como objeto de estudo a investigação da violência escolar materializada através do bullying e a violação de direitos humanos no cotidiano da escola. Esta pesquisa foi desenvolvida no IFMT Campus Cuiabá Bela Vista, com 130 estudantes dos cursos técnicos integrados ao Ensino Médio, no período 2017/2018. Foram analisados documentos institucionais vigentes de 2014 a 2018. O objetivo desta pesquisa foi compreender como a violência escolar, a prática do bullying e de violação de direitos humanos estão presentes nas relações cotidianas dos estudantes adolescentes do IFMT campus Cuiabá - Bela Vista. Os resultados apresentados surgiram dos entrelaçamentos entre as percepções, narrativas e documentos oficiais, que demonstraram que o bullying está presente no campus pesquisado, materializado através da violência simbólica, verbal e racial. Neste trabalho foram caracterizados 09 tipos de violência dos quais se pôde tecer suas particularidades. A partir de diretrizes e referenciais educacionais se percebe que as mudanças de concepções são fundamentais para a valorização de uma formação cidadã e humana, pautada na implementação de um currículo que viabilize a transdiciplinaridade da Educação em Direitos Humanos como balizadora das práticas pedagógicas do Campus.
\end{abstract}

Palavras-chave: Bullying. Cotidiano. Direitos Humanos.

\begin{abstract}
This article aims to study the investigation of school violence materialized through bullying and the violation of human rights in the daily life of the school. This research was developed at IFMT Campus Cuiabá Bela Vista, with 130 students from technical courses integrated to high school, in the period 2017/2018. The objective understand how school violence, the practice of bullying and human rights violations are present in the daily relationships of adolescent students IFMT campus Cuiabá - Bela Vista. The results presented emerged from the intertwining between perceptions, narratives and official documents, which demonstrated that bullying is present in the campus researched, materialized through symbolic, verbal and racial violence. In this work, 09 types of violence were characterized in which I was able to weave their particularities. Based on educational guidelines and references, it is perceived that changes in conceptions are fundamental for the valorization of a citizen and human formation, based on the implementation of a curriculum that makes possible the transdiciplinarity of Human Rights Education as a guiding point of the pedagogical practices of the Campus.
\end{abstract}

Keywords: Bullying. Daily.; Human rights. 


\section{INTRODUÇÃO}

Apresenta-se neste artigo um extrato dos resultados da pesquisa de Mestrado Acadêmico em Ensino (SILVA, 2019), tendo como objeto de estudo a investigação da violência escolar materializada através do bullying e a violação de direitos humanos no cotidiano da escola. Nesse contexto se visa compreender como a violência escolar, a prática do bullying e de violação de direitos humanos estão presentes nas relações cotidianas dos estudantes adolescentes do IFMT campus Cuiabá - Bela Vista.

Segundo o Ministério da Educação, a Educação em Direitos Humanos implica na implementação do Plano Nacional de Educação em Direitos Humanos, que envolve formação e construção de materiais didáticos, entre outras ações, que favoreçam a pesquisa e discussão sobre a temática e permita aos educadores e instituições se prepararem para a atuação neste campo (MEC, 2020), esclarecendo as diretrizes que cada cidadão possui e como o mesmo pode implementar ações e desenvolver uma cultura de paz. O fundamento dos Diretos Humanos é o valor primordial da pessoa humana, tendo quatro princípios orientadores para a educação escolar e perspectivas para a formação cidadã: dignidade da pessoa humana, igualdade de direitos, participação e co-responsabilidade pela vida social (BRASIL, 2007). A sensibilização da comunidade escolar perante os Direitos Humanos e suas temáticas, favorece ao combate e prevenção quanto ao bullying, que é uma forma de violência escolar, física ou simbólica, praticada com a característica de repetição e isolamento social da vítima (FANTE, 2005; FERRARI, 2020).

Pesquisar o cotidiano, enquanto uma forma de pesquisa social, que segundo Oliveira e Alves (2008), parte das especificidades da realidade concreta e de seus processos reais de construção e pelo desafio da "seleção e organização, análise e sistematização de dados complexos, inter-relacionados, misturados, articulados, muitas vezes de modo incompreensível, além de desorganizados do ponto de vista 'científico' têm sido atividades de pesquisa relevantes". As autoras, que são referência na pesquisa no/dos/com os cotidianos, revelam o entendimento desses aspectos diversos da vida cotidiana, que demandam outros tipos de procedimentos de pesquisa, que abarcam os aspectos singulares e diversos da realidade pesquisada. Ao buscar a compreensão da complexidade das situações reais e singulares constituídas cultural, histórico e socialmente, que fundamentam a concepção de que essa pesquisa de natureza qualitativa, descritiva e interpretativa.

Serão apresentados, neste trabalho, elementos básicos que referenciam a pesquisa no campo teórico e os principais resultados da pesquisa de campo. 


\section{REFERENCIAL TEÓRICO}

Os autores para o aporte teórico são: Certeau (2004, 2013), com os conceitos que abrangem a arte de fazer o cotidiano, invenção e táticas; Oliveira; Alves (2008) e Ferraço (2007), que têm fundamentado a concepção de pesquisa nos/dos/com os cotidianos da escola; Abramovay (2002, 2006), para auxiliar a compreensão da violência na escola; Fante (2005) e Silva (2010), para me ajudar a entender a questão do Bullying na escola.

Concebendo como indissociáveis teoria, métodos e vivências, que dialogam entre si e podem ser apresentados em uma linguagem compreensível, contextualizada e globalizada, em que se descreve a realidade vivenciada a partir da imersão no/do/com cotidiano. Essa arte de se recriar a concepção da pesquisa cotidiana como uma dimensão multifacetada, é fundamentada em Oliveira e Alves (2008, p. 51), que não apresenta a distinção das diversas dimensões: não se separa teoria e prática, os saberes formais e os saberes cotidianos, o modelo social e a realidade social, os dados relevantes e os irrelevantes cientificamente, os observadores e os observados, o conteúdo e a forma.

A prática cotidiana é pautada na obra de Michael de Certeau, A Invenção do Cotidiano, e aprofundado por pesquisadores cotidianistas, como Nilda Alves e Inês Barbosa de Oliveira (2008); essas defendem a subversão de paradigmas hegemônicos nos quais se tem formação, visando compreender como "os sujeitos se constroem como seres autônomos e o currículo produz práticas emancipatórias em ambientes fortemente regulados" (LOPES; MACEDO, 2011, p. 162). Essa prática emancipatória é uma teoria de resistência, em que os sujeitos praticantes são protagonistas de seus contextos, que visa a constituição de articulação entre os conhecimentos e as práticas.

Certeau (2004) apresenta o conceito do entrelaçamento de percursos, em que para o autor o espaço é concebido como um "conjunto de movimentos que aí se desdobram”, que não se fecha em si mesmo, mas abre novos caminhos para submergir na multidão, sendo um trabalho de cooperação, um confronto de experiências, engajamento e entrecruzamento dos sujeitos. Atrelado a este, o autor apresenta o conceito de mecanismos de resistência, que é uma forma dos mais fracos usarem de sua inventividade para inverter a lógica do dominante; no caso do bullying a vítima se empoderar em uma espécie de neutralização às investidas do agressor.

O protagonismo jovem é uma forma de tática de praticantes como um mecanismo de resistência (CERTEAU, 2004, p. 45), em que os chamados fracos se opõem à lógica dos chamados fortes. Essas táticas criam uma microrresistência, que visa fortalecimento do sujeito, fazendo com que o mesmo seja protagonista de sua história, garantindo seu espaço no cotidiano, 
rompendo com modelos preestabelecidos e com a banalização do mal que ainda é presente no cotidiano escolar.

Neste contexto de entrelaçar as ideias, os percursos e os sujeitos praticantes é que a escrita se projeta nessa direção, nesse movimento de ir e vir, de liberdade textual e busca pelo anseio dos sujeitos praticantes do cotidiano, de não ser mais o mesmo, pois o contato com o outro e sua realidade nos remete a mudanças de nossos paradigmas e certezas.

\section{Metodologia}

A concepção da pesquisa no/do/com cotidiano abarca o conceito de que estar no espaço pesquisado abre a pluralidade de possibilidades de articulações, que erguem esse cotidiano a uma condição de espaço-tempo privilegiado de produção da existência e dos conhecimentos, crenças e valores que lhes dão sentido. Oliveira e Alves (2008, p. 51) fundamentam ainda que os estudos cotidianos devem ser considerados em sua complexidade e se compõem por elementos articulados e indissociáveis das metodologias que são estudadas por seu viés.

Estar no espaço, compartilhar experiências e vivenciar a realidade, se articula com a concepção de "olhar de dentro", trazida por André (2001). Segundo o autor, o pesquisador era pensado como um sujeito "de fora", em função de heranças epistemológicas das ciências da natureza; porém, nos últimos dez anos, há a valorização do olhar "de dentro", se analisa o trabalho e a experiência do próprio pesquisador, nos quais, este desenvolve a pesquisa com a colaboração dos participantes.

As observações dos acontecimentos exigem uma observação do/no/com o cotidiano que parte do olhar sobre as diversas fontes em que foram geradas. Para tal, foram utilizados quatro procedimentos de coleta de dados: primeiro, questionário online; segundo, a entrevista com as estudantes/bolsistas; terceiro, a entrevista com as profissionais psicóloga e assistente social, que compõem a equipe multiprofissional do campus da pesquisa; e quarto, a análise dos documentos institucionais que norteiam os cursos dos sujeitos pesquisados (Cf.: BODGAN; BIKLEN, 1994). Houve a participação de 130 estudantes dos cursos Técnicos em Química e Meio Ambiente integrados ao Ensino Médio, na pesquisa on line, entrevistas com 03 estudantes bolsistas e a entrevista com 02 membros da equipe multiprofissional. Esses dados estão situados em momentos distintos, porém foram se complementando para compreender os movimentos dos sujeitos praticantes e suas táticas subversivas, em que, além de ouvir os sujeitos da pesquisa, se busca analisar os dados obtidos e as ações educativas praticadas no cotidiano desta instituição de ensino pelo currículo da mesma, verificando se os documentos existentes propõem alguma 
forma de enfrentamento desta problemática, visando ações que gerem possíveis mudanças no referido cotidiano; estes procedimentos compõem o processo de análise dos dados coletados, em que cada etapa da pesquisa se interliga pela percepção de como as ações se constituem no cotidiano escolar; em um sentido descritivo e transversal, próprio das pesquisas sociais de cunho qualitativo (BODGAN; BIKLEN, 1994; MOTA, et al, 2017).

Essa metodologia de pesquisa concebe a linguagem, as práticas e as coisas como inseparáveis, pois procura trabalhar com a vivência, com a experiência, com o dia a dia, com a compreensão das estruturas e instituições como resultantes da ação humana. $\mathrm{O}$ uso da abordagem qualitativa se justifica pela necessidade de observar as pessoas em seu próprio contexto interacional, ou seja, no ambiente em que a interação ocorre naturalmente. Autores como Bogdan; Biklen (1994, p. 21) consideram como o foco central da pesquisa social o desvelar a ordem oculta do mundo informal da vida cotidiana, mostrando interesse em como as pessoas espontaneamente se expressam e falam sobre o que é importante para elas e como elas pensam sobre suas ações e as dos outros.

Ao pesquisar o cotidiano escolar, o currículo escolar, as formas de violência, violações e toda sua dimensão teórico-metodológica, assumem o entrecruzamento com a realidade e prática escolar, não vislumbrando as mesmas como distintas e separadas em partes, mas complementares e tecidas em um todo, em que os interesses do coletivo e suas demandas são os pontos principais dessa teia. A análise dos dados coletados em cada etapa da pesquisa se realiza a partir destes fundamentos, no âmbito do discurso e suas implicações práticas, intercruzando as experiências e cada etapa do processo.

\section{Resultados}

Apresenta-se uma caracterização do perfil dos sujeitos envolvidos na pesquisa e se contextualiza com seus próprios relatos, que compõem a tessitura do texto. Os sujeitos participantes da pesquisa foram 135 pessoas, em sua maioria do sexo feminino, com as idades entre 13 a 39 anos.

A pesquisa teve 130 participantes da que responderam online com os seguintes resultados: $32(24,6 \%)$ dos estudantes alegam ter tido seus direitos violados na instituição, sendo 17 do sexo feminino e 15 do sexo masculino. O maior número de respondentes foi do sexo feminino e manteve a proporção de respostas sobre ter seus direitos violados na escola pelos estudantes do sexo feminino. 
As estudantes bolsistas pesquisadas trazem suas concepções sobre bullying e violência quando percebem que esse existe e que ainda deixa marcas em quem sofre:

Para mim todas as coisas que são feitas para desmerecer e desfavorecendo outra pessoa acaba sendo bullying, isso acarreta não só para o agressor das palavras ou gesto que faz, muitas coisas ruins para quem está recebendo e isso desencadeia tantas outras coisas negativas, como doenças e até mesmo depressão. (Estudante/Bolsista 2, 2018).

Que esse movimento complexo de tentar definir violência e a percepção dos estudantes como essa se materializa no contexto escolar, pois como os estudantes trazem o entendimento de que é uma brincadeira e não há consequências de seus atos, apenas ficam as marcas em quem sofre; se observa o entendimento da legitimação ou naturalização do bullying, fato sabido, porém não afrontado, dando o entendimento de que pode haver uma banalização do mal, termo trazido pela pensadora alemã Hannah Arendt (2008); a mesma reflete sobre a capacidade de pensar do ser humano como uma forma da não prática do mal; a autora traz no bojo de suas contribuições o vínculo existente entre o pensamento e a ação humana.

Para entender a percepção dos estudantes sobre a prática do bullying, os mesmos responderam se já praticaram bullying com os colegas e, dos entrevistados, 24 estudantes $(18,46 \%)$ relataram que já praticaram bullying com colegas na escola e alegaram motivos como: porque me senti provocado, por brincadeira, porque acho que eles merecem, porque fui idiota e não sei.

Nesse momento se destaca a estrutura do questionário de pesquisa e o desdobramento da questão fechada 09, em 24 itens (das letras "a" a "x"), estes resultados representam o cerne dos tipos de bullying praticados no Campus Cuiabá - Bela Vista e servem para desvelar as práticas que podem ocorrer no contexto pesquisado. O mesmo apresentou de forma geral os resultados conforme o Quadro 1 e a análise dos dados apresentados.

Quadro 1 - Dados do questionário da pesquisa

\begin{tabular}{|c|c|c|c|}
\hline Marque em caso afirmativo & $\begin{array}{c}\text { Muitas } \\
\text { vezes }\end{array}$ & $\begin{array}{c}\text { Algumas } \\
\text { vezes }\end{array}$ & $\begin{array}{c}\text { Nenhuma } \\
\text { vez }\end{array}$ \\
\hline a) Insultam-me & $4 \%$ & $40 \%$ & $56 \%$ \\
\hline b) Colocam-me apelidos vergonhosos & $7 \%$ & $37 \%$ & $56 \%$ \\
\hline c) Ameaçam-me & $2 \%$ & $7 \%$ & $91 \%$ \\
\hline d) Dizem coisas negativas sobre mim ou sobre minha família & $2 \%$ & $32 \%$ & $66 \%$ \\
\hline e) Insultam-me por causa de alguma característica física & $15 \%$ & $31 \%$ & $54 \%$ \\
\hline f) Levo socos, chutes e empurrões & $0 \%$ & $5 \%$ & $95 \%$ \\
\hline g) Riem de mim e me apontam & $2 \%$ & $31 \%$ & $54 \%$ \\
\hline h) Fazem com que os outros não gostem de mim & $4 \%$ & $15 \%$ & $81 \%$ \\
\hline i) Inventam que eu furto coisas de meus colegas & $0 \%$ & $2 \%$ & $98 \%$ \\
\hline j) $\quad$ Puxam meu cabelo ou me arranham & $1 \%$ & $4 \%$ & $95 \%$ \\
\hline k) Não me deixam fazer parte do grupo de amigos & $4 \%$ & $16 \%$ & $80 \%$ \\
\hline l) Estragam minhas coisas & $2 \%$ & $5 \%$ & $93 \%$ \\
\hline m) Ignoram-me completamente, me dão um “gelo” & $3 \%$ & $18 \%$ & $79 \%$ \\
\hline
\end{tabular}




\begin{tabular}{|c|c|c|c|c|}
\hline $\mathrm{n})$ & Insultam-me por minha cor ou minha raça & $3 \%$ & $10 \%$ & $87 \%$ \\
\hline o) & Pegam meu dinheiro ou minhas coisas sem minha permissão & $2 \%$ & $3 \%$ & $95 \%$ \\
\hline p) & Fazem piadas do meu sotaque & $2 \%$ & $7 \%$ & $91 \%$ \\
\hline q) & Encostam-me contra a parede & $0 \%$ & $2 \%$ & $98 \%$ \\
\hline r) & Forçam-me a agredir outro colega & $0 \%$ & $0 \%$ & $100 \%$ \\
\hline s) & Humilham-me por minha orientação sexual & $1 \%$ & $92 \%$ & $7 \%$ \\
\hline t) & Perseguem-me dentro ou fora da escola & $1 \%$ & $7 \%$ & $92 \%$ \\
\hline u) & Assediam-me sexualmente & $0 \%$ & $1 \%$ & $99 \%$ \\
\hline v) & Fui obrigado a entregar meu dinheiro ou minhas coisas & $0 \%$ & $1 \%$ & $99 \%$ \\
\hline w) & Abusam sexualmente de mim & $0 \%$ & $2 \%$ & $98 \%$ \\
\hline $\mathrm{x})$ & Fazem agressões virtuais (redes sociais) & $1 \%$ & $12 \%$ & $87 \%$ \\
\hline
\end{tabular}

Fonte: Autora - dados da pesquisa (2017).

Após a tabulação dos dados houve a construção, pelo grupo de pesquisa, de um modo de análise para classificar as perguntas fechadas por blocos, juntando os tipos de violências em categorias; para olhar essas questões do micro para o macro, percebendo quais micro violências apresentadas nos dados coletados podem representar um universo bem significativo de violências e violações dos direitos materializados através da prática dos diferentes tipos de bullying vivenciados nesse cotidiano escolar. As classificações das violências foram distribuídas da seguinte forma:

Quadro 2 - Tipos de violência

\begin{tabular}{|l|l|}
\hline \multicolumn{1}{|c|}{ Tipo de Violência } & \multicolumn{1}{c|}{ Letras referentes } \\
\hline Violência de Orientação sexual & "s" \\
\hline Violência por aparência física & "e" \\
\hline Violência Verbal & "a", "b", "c", "d", "g", "p" \\
\hline Exclusão Social no ambiente escolar & "h", "m", "k" \\
\hline Violência Física & "f", "j", "q", "r", "t" \\
\hline Violência Racial & "n" \\
\hline Violência Sexual & "u", "w" w" "co", "v" \\
\hline Danos materiais & "i", "l" "o" \\
\hline Cyberbullying & "x" \\
\hline
\end{tabular}

Fonte: Autora - dados da pesquisa (2017).

Silva (2010) traz o desdobramento dos tipos de bullying existentes, explicitando 6 tipos de bullying, sendo: físico, verbal, psicológico, material, sexual e virtual, e considera que todos se assemelham no que concerne violar a integridade do outro. $\mathrm{O}$ artigo $3^{\circ}$ da Lei de Intimidação Sistemática (Lei $\mathrm{n}^{\circ}$ 13.185/2015), também chamada de lei antibullying, categoriza o bullying em 6 tipos (BRASIL, 2015). O ponto central dessa busca por conceitos é que tanto o bullying quanto a violência escolar são a materialização da violação dos direitos humanos, que fere princípios éticos e de cidadania das vítimas (FELIZARDO, 2017).

Para ilustração da construção do grupo de pesquisa segue imagem abaixo, que complementa as formas trazidas pela Lei $n^{\circ} 13.185 / 2015$ e por Fante (2005), pois houve o entendimento de que as violações de direitos transitam em conjunto e não se classificam e se 
mensuram isoladamente, é necessário analisar todo contexto e complexidade das formas como a violência escolar se apresenta, pois compreende-se que essa não é isolada e descontextualizada.

Figura 1 - Formas de violência escolar

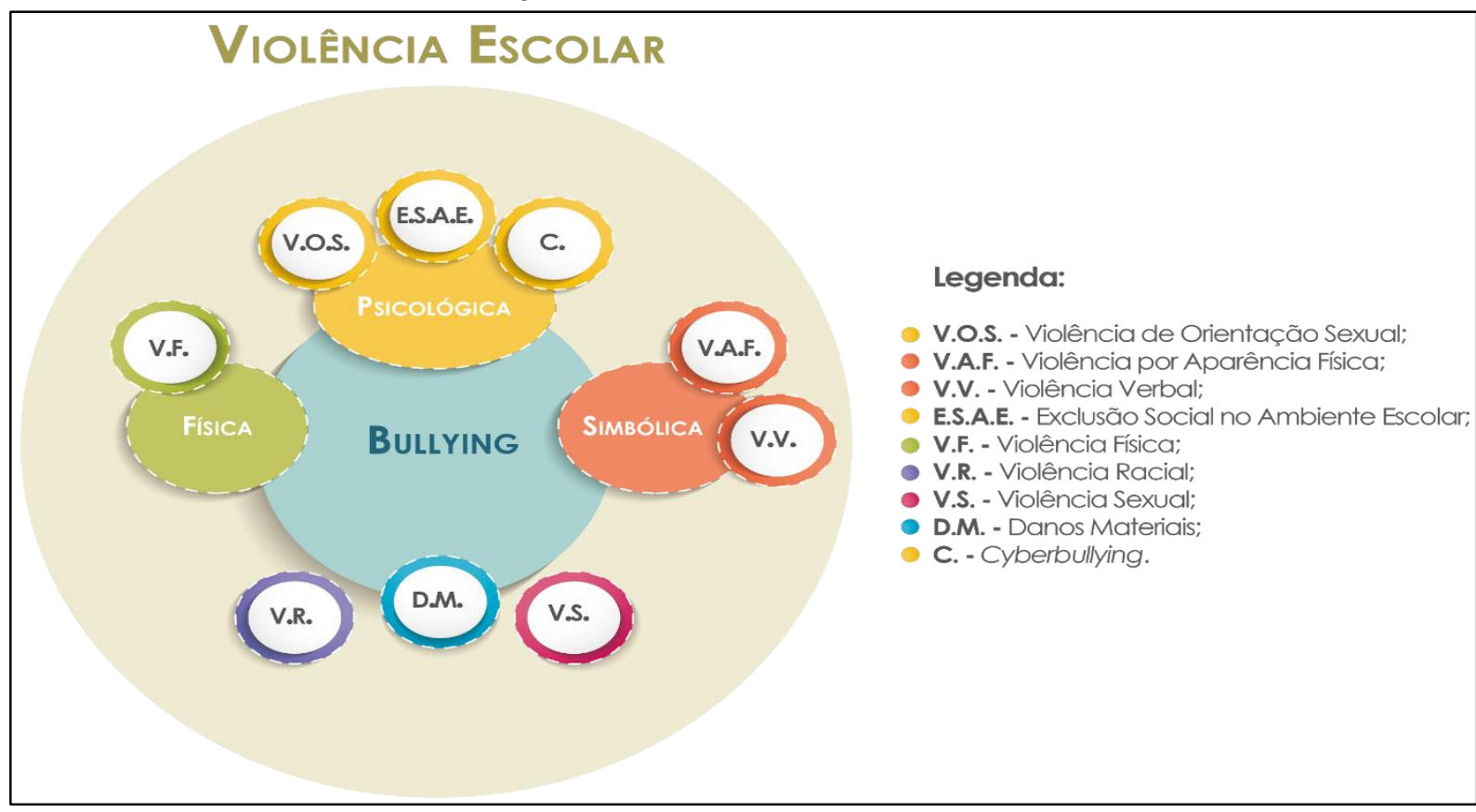

Fonte: Autora - dados da pesquisa (2017)

A violência escolar pode ser simbólica e psicológica ao mesmo tempo quando um estudante insulta o outro em função de sua característica física, por exemplo. Essas nuances são importantes para a compreensão de que esses atos não podem ser banalizados ou naturalizados.

No entendimento de que algumas ações têm implicações mais amplas é que se traz a proposta da pesquisa em acrescentar três tipos de categorias de bullying, pois se entrecruzam com outras formas de violência, tornando-se mais específicas em sua identificação.

Quadro 3 - Relação das violências da pesquisa x Lei Antibullying

\begin{tabular}{|l|l|}
\hline \multicolumn{1}{|c|}{ Tipo de violência da pesquisa } & \multicolumn{1}{c|}{ Lei antibullying } \\
\hline Violência de Orientação sexual & Sexual, Psicológico/Moral \\
\hline Violência por aparência física & Psicológico/Moral, Verbal \\
\hline Violência Verbal & Verbal \\
\hline Exclusão Social no ambiente escolar & Psicológico/Moral \\
\hline Violência Física & Físico \\
\hline Violência Racial & Psicológico/Moral \\
\hline Violência Sexual & Sexual \\
\hline Danos materiais & Material \\
\hline Cyberbullying & Virtual \\
\hline
\end{tabular}

Fonte: Autora - dados da pesquisa (2018). 
Um estudante relata uma situação de bullying homofóbico na instituição, apesar de pouca incidência apresentada no item muitas vezes (1\%), mas um número considerável de algumas vezes (92\%), essa pode estar velada nas relações. Quanto ao fato, o estudante relata:

Nunca sofri o bullying diretamente, mas ouvir do seu lado que a sua orientação sexual é uma aberração, que não deveria existir, ou ver ela sendo usada como xingamento não é o que eu chamo de respeito ou ambiente saudável. (Estudante, 16 anos, Meio Ambiente).

O IFMT, através de sua Política e Metas para Direitos Humanos, contidos em seu Plano de Desenvolvimento Institucional, assegura que é preciso perceber a orientação sexual como um elemento integrante do processo de construção de uma cidadania ativa. Isto é, para além das preocupações com o desenvolvimento de ações educativas voltadas para a compreensão da importância de se respeitar e valorizar a diversidade sexual e a igualdade de gênero, sendo imprescindível que seja levado em consideração que a inclusão social só será plena se dessa fizer parte a inclusão relacionada à diversidade sexual (IFMT, PDI, 2014, p. 83).

Os caminhos e as escolhas devem ser responsáveis, ativos e respeitosos. Devem ser, sobretudo, críticos frente ao modelo social vigente, com vistas à transformação social na busca pela justiça e pela igualdade (IFMT, PDI, 2014, p. 56).

Frente a este contexto, Pereira et al. (2015, p. 1490) falam da importância de debater essas questões na escola, e que não podem cair no esquecimento, que é uma questão de Direitos Sexuais entendidos como Direitos Humanos Universais e Fundamentais, mais especificamente ao princípio da dignidade da pessoa.

Outro dado que se considera elevado foi quanto à aparência física. O questionário no item "e" da questão 9, fica o item mais alto da prática de bullying, 15\% dos sujeitos participantes alegam ter sofrido algum tipo de constrangimento com relação a sua aparência física. Este tipo de bullying por aparência física é bem presente na realidade do Campus Cuiabá - Bela Vista, pois ao se agrupar os números das alternativas "muitas vezes" e "algumas vezes" se tem $46 \%$ (quarenta e seis) dos estudantes pesquisados que já foram insultados por sua característica física.

Esta situação é uma violência praticada no ambiente escolar e, segundo Abramovay (2002, p. 24-25), tem variáveis endógenas e exógenas, que são relativas ao interior e exterior dos muros da escola, com influência de outros ambientes e instituições pelas quais os estudantes transitam. A autora traz como aspectos exógenos algumas questões que precisam ser consideradas pela escola para compreender seu meio, como questões de gênero, relações raciais, situações familiares, influências da mídia, espaço social no qual a escola está inserida 
A estudante/bolsista pesquisada trouxe em sua fala um relato de situação vivenciada pela mesma, em que fala sobre ser vítima de intimidação por alguma característica física:

[...] é de não aceitar o diferente né, não aceitam! Já aconteceu comigo em relação ao meu corpo por eu ser muito magra e tal, e tipo, na época foi uma pessoa que era a minha colega que falou, então tipo, eu fiquei chateada, mas tipo levei na boa, fiquei chateada, sempre fiquei chateada, tipo assim, não briguei e depois. Isso já faz bastante tempo, mas foi aqui no IF e quando participando do estudo e entendendo mais sobre o bullying, você consegue olhar para isso e caracterizar, "nossa, isso foi realmente bullying". Eu acho que tem uma mínima importância você conhecer, que você consegue olhar para as coisas mínimas e caracterizar e falar bem assim "isso aqui foi bullying, isso aqui não podia ter acontecido”. (Entrevista Estudante/Bolsista 1, 2017).

O relato acima é um dos dados preocupantes, pois cerca de $15 \%$ dos estudantes participantes da pesquisa sofreram esse tipo de violência em função de a uma característica física, do cabelo, do formato do rosto, dos lábios, do nariz, da estrutura física, por ser gordo ou magro, por ser alto ou baixo... enfim, por características pessoais que tornam cada indivíduo único.

Pelos relatos dos estudantes pesquisados, a característica física que evidenciou na pesquisa foi quanto ao peso; os gordinhos relatam que se sentem constrangidos com as piadas sobre seu físico. Como no relato da profissional, que diz:

em uma sala que uma menina sofreu bullying desde o primeiro dia de aula por ser gorda estar acima do peso, E o pessoal da sala fala que ela chega atrasada porque estava comendo Mac Donald e todo mundo ria e ela se sentia extremamente ofendida pois desde o primeiro dia de aula ela não queria estar dentro do campus por causa disso, foi com muito trabalho que ela conseguiu ir contornando a situação... mas ela se sentia muito mal com tudo o que acontecia. (Profissional 1, 2018).

Essa forma de bullying representa uma característica bem singular do jovem, a busca pelo estereótipo e padrão de beleza que é disseminado pela mídia, em que aqueles que fogem desse padrão, relembrando de Procusto, também são dispensados.

A profissional da instituição traz uma consideração importante sobre os padrões preestabelecidos que causam situações de distanciamento entre os estudantes:

O adolescente que sofre bullying é um adolescente que não está nos padrões estabelecidos ali para aquele grupo não é o suficiente... não é forte o suficiente, não é bonito suficiente, não é magro suficiente, não é branco suficiente então a gente precisa parar de estabelecer esses padrões (Profissional 1, 2018).

Helen Gonçalves (2004), em sua tese, traz a questão do padrão de beleza e da feminilidade em voga na sociedade, que estabelece padrões para o corpo, cabelo, pele. A autora traz a narrativa que "quando o corpo não atende as exigências do universo feminino e masculino, não pode faltar o recurso do moletom enrolado na cintura, ou o vestido no tamanho maior para encobrir as imperfeições" (GONÇALVES, 2004, p. 201). Esses padrões 
estabelecidos são perniciosos, pois a partir da métrica da estética que os jovens podem ser medidos e comparados, e o que "são as suas imperfeições ou as características mais pessoais que o identificam e dão origem apelidos nem sempre apreciados" (GONÇALVES, 2004, p. 202).

Esse complexo universo das relações juvenis pode ser uma oportunidade da escola, através de sua relação pedagógica, pensar e fazer um trabalho pedagógico de promoção ao autoconhecimento desses jovens para que coletivamente transponham esse momento de suas vidas com mais serenidade e com superação do desafio da convivência humana.

Tratando a questão do bullying em função da à aparência física, percebe-se que esse não vem sozinho, pois uma violência gera outras formas de violências; quando o estudante agressor pratica seus atos de incivilidades pode desencadear outros processos de desrespeito e ofensas. $\mathrm{O}$ agressor, quando trata pejorativamente a vítima em decorrência de suas características físicas, inevitavelmente pratica a violência verbal. A violência verbal também está presente no cotidiano da pesquisa, os insultos foram apontados como a violência verbal mais praticada.

A violência verbal engloba insultar, chamar nomes ou apelidos desagradáveis, gozar, fazer comentários grosseiros que visem salientar qualquer aspecto físico ou deficiência dos colegas. Abramovay (2002, p. 48) traz que a expectativa social é de que a escola atue no sentido da promoção e da difusão de condutas pautadas pelo respeito, pelo diálogo, pela valorização da escuta, configurando-se como espaço de interações positivas entre os atores que nessa convivem. Entretanto, as agressões verbais são comuns e banalizadas no dia-a-dia, traduzindose em desrespeito, ofensas, modos grosseiros de expressão, xingamentos e da "zoeira". Como a narrativa da estudante, quando fala de sua vivência:

Há uns anos atrás, no Ensino Fundamental, sofri bullying por conta do meu peso, mas desde que entrei no IF, teve apenas uma vez, no primeiro ano, que um cara (que estava no último ano) falou para mim ir rolando pela rampa que eu iria mais rápido (o que nem faz sentido porque emagreci e nem estou gorda assim u.u). Mas na escola, direto, vejo pessoas que de um jeito ou outro, disfarçado de brincadeiras, sofrem algum tipo de bullying, por sua etnia, sotaque, condições financeiras etc, é muito comum andar pelos corredores e ouvir certos comentários. (Estudante, 16 anos, Meio Ambiente).

Esse relato é uma demonstração que o bullying tem vertentes que caminham juntas, pois iniciou por características físicas e virou motivo de piadas e deboche com a estudante vítima, tornando-se uma agressão verbal.

Abramovay (2006, p. 131) ainda pondera que as agressões verbais pedem mais reflexão quanto ao seu significado. Apesar de, muitas vezes, serem consideradas brincadeiras corriqueiras, essas têm como objetivo a humilhação, a exposição ao ridículo, a ofensa. Esse tipo 
de violência não somente aflige, mas, segundo a autora, agride seriamente, permeando as relações interpessoais, passando a determinar a forma como os membros da comunidade escolar se comunicam e interagem entre si, dentro de um perfil agressivo que é externalizado através de ofensas, insultos, difamações, desacatos e visões preconceituosas apoiadas em estereótipos.

A violências verbais mais praticadas no cotidiano do Campus Cuiabá - Bela Vista são o item "b" - Colocam-me apelidos vergonhosos; em média, cinco estudantes da pesquisa dizem ter recebido algum apelido que os constrangeu por mais de quatro vezes; quarenta e oito estudantes afirmam que passaram por esse constrangimento por até três vezes. Seguido pela "a" - insultam-me, cinquenta e dois estudantes da pesquisa alegam ter sofrido pelo menos três vezes essa ação; e em média cinco estudantes relataram que sofreram mais de quatro vezes esse tipo de violência.

Relato 2:

Sim, eu já sofri bullying por conta do meu corpo, me insultavam, faziam piadas, colocavam apelidos em mim, eu era a excluída da sala porque falavam que eu era metida. Foi assim por um tempo, e durante esse tempo eu sempre ficava quieta no meu canto, as pessoas olhavam mas falavam que era brincadeira, mas eu não achava isso, me sentia mal. Até que eu mudei de escola e no começo não foi muito diferente, mas agora está bem melhor. (Estudante, 16 anos Meio Ambiente).

Nestes dois relatos, os estudantes falam sobre a violência verbal associada a danos materiais, a violência por aparência física e de exclusão no ambiente escolar. São características já narradas anteriormente, de que o bullying não se limita a apenas um tipo de ação.

O terceiro item com maior índice foi o "d"- dizem coisas negativas sobre mim ou sobre minha família, estendendo a agressão a outro membro da família do estudante. Quarenta e um estudantes da pesquisa alegam ter sofrido pelo menos três vezes essa ação; e aproximadamente três estudantes relataram que sofreram mais de quatro vezes esse tipo de violência.

Relato 3

Já vi muitos alunos do campus sendo 'atacado', geralmente com 'piadinhas de mal gosto' as mais comuns que eu já vi, são por causa do sotaque, nome ou por cor de pele. (Estudante, 15 anos Meio Ambiente).

Esse tipo de violência pode não ser desencadeado por alguma motivação aparente. Segundo Abramovay (2006, p. 143), de alguma forma, ofender o outro, podendo tocar em pontos que revelam a sua vulnerabilidade, a sua fraqueza, não se limitando a barreiras de gênero e, em alguns casos, evidenciando questionamento da autoridade. A autora entende ainda que essa atitude é contrária à expectativa da função da escola, com uma atuação contrária à aprendizagem para a vida social. 
Um grande problema desse tipo de violência é a naturalização, que pode ser considerado uma fase natural da vida estudantil, como uma espécie de "tradição cultural" (BARBOSA, 2007), e a banalização de sua prática (ARENDT, 1999), que, conforme estudos de Abramovay (2006, p. 143), por seus significados, por vezes, busca-se meios para justificar a sua ocorrência. As agressões verbais, como outras, quando recorrentes e se não são combatidas por meio de punições, repreensões, diálogos críticos e desestímulos podem criar sentimento de apatia, de impotência, de tristezas, minando vontades, contribuindo para a domesticação de corpos, moldando sujeitos acríticos e desencadeando um possível processo de exclusão social no ambiente escolar.

Abramovay (2006, p. 131) relata que a opção pelo isolamento e pelo recolhimento na sala de aula é outra atitude que pode ser observada em estudantes vítimas de agressões verbais. Alguns preferem desenvolver uma estratégia de defesa, que se traduz em uma forma de autoexclusão, que pode gerar dificuldades de relacionamento e afetar o processo de ensino aprendizagem do estudante.

O se isolar ou ser ignorado por seus pares dentro de uma instituição de ensino fere o princípio da escola de ser um espaço de socialização. Esse tipo de bullying foi evidenciado através de relato feito por um sujeito da pesquisa, que diz:

no IFMT vejo que ocorre mais exclusão de certos estudantes, que acabam ficando sozinhos, quando reprovam, quando vem de outras escolas, ou até mesmo da sala que a sala inteira ignora. (Estudante Meio Ambiente, 18 anos, $3^{\circ}$ ano).

O relato de um estudante demonstra que essa pode ser uma prática presente na vida de estudantes que tiveram reprovação e mudaram de sala. Considera-se que esse tipo de situação necessita de uma atenção, pois o acolhimento tem papel fundamental para a permanência do mesmo, podendo ser responsabilidade dos docentes, coordenadores e dos demais estudantes; interessante que seja pensado no acompanhamento psicológico e pedagógico desses estudantes, para prevenir atos de isolamento e não adaptação ao novo contexto e à nova turma.

As análises dos dados da pesquisa já sinalizam que a escola pesquisada não está isenta desse tipo de prática, sendo necessário olhar para esse cotidiano visando criar estratégias em que os novos fazeres sejam pautados na demanda por um ambiente mais acolhedor, saudável e em que haja respeito. O bullying e outros atos de violência não podem ser tratados como um fato isolado e desconexo, isso demanda um olhar multidimensional através de práticas transdisciplinares, que permite que usar óculos que melhorem a visão sobre os fatos e enxergar 
a situação claramente, não mais como um vulto, na ilusão de que punir, julgar e excluir sejam alternativas para o real problema.

As falas das profissionais foram fundamentais para compreender o cotidiano do IFMT Cuiabá - Bela Vista; com relação a este tipo de bullying praticado no campus, as profissionais relatam suas vivências e dizem:

[...] Eu tenho uma perspectiva de marcadores sociais quanto a isso, porque eu acho que o bullying e a violação de direitos humanos, estão presentes na escola como em outros lugares também e a escola acaba reproduzindo certos tipos de padrões, de pensamento, de beleza, E de ser mesmo que reforça os estereótipos que reforçam o bullying. (Profissional 1).

[...] Acredito que tem alguns determinantes sociais que interferem nesta questão, estas percepções de violência, de gênero, racismo, preconceito, desigualdade social, tudo isso influencia para estas atitudes agressivas. (Profissional 2).

Para as profissionais as questões sociais também são determinantes ao estabelecerem as relações cotidianas escolares. O tratamento desigual dos sujeitos praticantes do cotidiano, demonstra que as práticas pautadas nas mais variadas situações sociais são sustentadas por uma ideia de superioridade econômica. Evidenciando que em todos os aspectos apontados há uma relação de desigualdade prezada por questões sociais, econômicas, de gênero, racial, religioso ... Enfim, as diferenças ainda causam afastamentos e fomentam a discriminação.

A violência que não foi evidenciada no campus foi a violência física, essa prática ficou sem apontamentos que causassem preocupação no cotidiano pesquisado. Quando se descrevem os tipos de bullying e violências da pesquisa, a violência física aparece com números poucos expressivos; segundo as profissionais houve apenas 1 registro de brigas com agressões nos quatro anos. Segundo a profissional entrevistada 2, nos tipos de bullying que acontecem no campus não é evidente o bullying que envolva agressão, porém, acontecem situações de humilhação, de ofensas, de isolamentos e de difamação.

A violência que é tratada a seguir é presente no campus da pesquisa com relatos de casos vivenciados por estudantes que foram ofendidos por sua cor (3\%, muitas vezes e $10 \%$ algumas vezes).

Os dados apresentados, de $13 \%$ dos pesquisados já terem sido insultados por conta de sua cor, se fortalecem através dos relatos dos estudantes e das profissionais quando relatam situações vivenciadas no campus relacionados a esta problemática. Quando questionados se já sofreram ou viram alguém sofrendo bullying na escola, alguns estudantes relataram que

Sim, um colega de turma me ofendeu a fazer piadinha com meu cabelo em sala de aula pois sou negra do cabelo crespo. (Estudante, 19 anos, Meio Ambiente). 
O depoimento demonstra que o preconceito ainda está presente em algumas relações, em virtude do racismo, que é o fator que leva a discriminação. Essa relação está intrinsecamente ligada à relação de suposta superioridade das raças; conforme Quijano (2005) conceitua, que povos conquistados e dominados foram colocados em uma posição de inferioridade naturalizada, em uma relação binária inferior/superior, e isso ainda é legitimado em frases como as narradas, pois a supremacia branca/europeia ainda se coloca como superior a outras características humanas.

Também se discute, como reforço de posturas racistas, a legitimação social de um certo padrão de beleza na sociedade que não contempla a valorização das características físicas da população afro-brasileira. Abordam-se, assim, percepções construídas acerca do cabelo dos jovens afrodescendentes, considerando que esse constituinte identificador de uma raça, historicamente, é assinalado para estigmatizar, mas tem potencialidades de simbologia identitária, sendo ressignificado em linguagens de movimentos sociais, como o movimento negro, para afirmação de autoestima e beleza (ABRAMOVAY, 2006, p. 204).

Durante o andamento da pesquisa houve uma situação que envolveu cyberbullying (tema abordado mais adiante), com conotação racista em virtude do cabelo da estudante. No episódio, uma estudante do curso de Meio Ambiente, em virtude da falta de consenso sobre um assunto que envolvia duas turmas distintas, envia no grupo de WhatsApp da sua sala um áudio com o comentário que, "gostaria de pegar o cabelo dela com um Bombril e limpar toda a sala que ela sujou", dando a conotação de que o cabelo da colega fosse esponja de aço e que a mesma era suja, além de iniciar o comentário com ofensas pejorativas.

Levanta-se a discussão para um tipo de violência que mata, que fere a alma e traz dor imensurável à vítima. A violência sexual está relacionada às questões de gênero, de misoginia e de violência doméstica (GIFFIN, 1994), pois muitos adolescentes e jovens estudantes se relacionam afetivamente, e em seus relacionamentos amorosos pode haver situações de possessividade e abuso entre os mesmos. Os números apresentados na pesquisa online não expressam a existência dessa prática entre os estudantes, mas alguns relatos demonstram que, apesar de poucos, existem estudantes que sofreram assédio e que precisaram de apoio da escola e família para mitigar essa gravíssima problemática.

Silva (2010) traz o conceito da forma de bullying com o aspecto sexual caracterizado, como abusar, violentar, assediar e insinuar; a autora relata que "esse comportamento desprezível costuma acontecer entre meninos com meninas, e meninos com meninos. Não raro 
o estudante indefeso é assediado e/ou violentado por vários 'colegas' ao mesmo tempo" (SILVA, 2010, p. 24).

Ao tecer as redes e conexões entre os dados coletados e as narrativas dos sujeitos participantes pode-se vislumbrar o contexto do campus quanto a danos morais e materiais. Os dados da pesquisa online apresentam uma baixa incidência desse tipo de bullying. Pondera-se que, apesar do índice baixo, o cuidado e zelo pelo patrimônio pessoal devem ser preservados pela escola, além dos cuidados com seus próprios pertences, e a escola tem providenciado armário com chaves para que possam guardar seus pertences, para evitar situações de furtos no interior da mesma. Conforme Abramovay (2006, p.16), existe o discurso da normalidade de tais ocorrências, porém, segundo a autora, "se constata que há uma relação entre a existência de furtos e a sensação de insegurança".

Esta é uma forma de bullying que tem registros no regimento disciplinar discente, no qual essa prática é tida como uma infração GRAVÍSSIMA, podendo o praticante receber sanções que gerem seu afastamento, até mesmo sua transferência.

As ocorrências de furtos presentes na escola pesquisada foram registradas oficialmente através de processos aos coordenadores de curso, sendo que em 2017 foram 4 casos; segundo o registro, são furtos de carregador de celular, celular, uniforme escolar e livros didáticos; já no ano de 2018 foram 5 casos com os mesmos itens. Porém esse número pode ser maior, por se entender que muitos estudantes não abrem processo ou comunicam o fato oficialmente.

Os pais procuram a escola para saber quais tratativas foram tomadas e como seus filhos devem proceder, na fala da Profissional 1, que registra o atendimento à família da vítima de furto,

geralmente os estudantes pedem para que seus pais venham a escola quando se trata de situações de roubo e furto, nem tanto de ofensas e humilhações, mas geralmente quando tem furtos os pais vem atrás para saber que eu vou fazer pelo celular. (Profissional 1, 2018).

Oficialmente houve 09 ocorrências em 02 anos, número que pode ser considerado relativamente baixo se comparado a outros contextos, porém precisam ser enfrentados para reduzir ainda mais esse nível, para que permaneça um clima de segurança e confiança entre os estudantes, pois, em ambientes em que a violência e o medo se instalam, de forma sutil ou aberta, impera a lei do silêncio e a lei do mais forte, até quando se trata de pequenos furtos. A lei do mais forte não se legitima apenas pela ameaça da violência, "é também alimentada por uma cultura que preza o considerado mais forte, o vencedor, desprezando o que perde - comum 
expressão da contravenção em assaltos - o que apanha, o que é furtado" (ABRAMOVAY, 2006, p. 265).

Finalizando a análise e conceituação dos tipos de violência, enfatiza-se uma que extrapola o mundo real e toma proporções que avançam rapidamente através da internet, que é o chamado cyberbullying.

A Lei $\mathrm{n}^{\circ} 13.185$, de 6 de novembro de 2015, que instituiu o programa de combate à intimidação sistemática, caracteriza cyberbullying quando ocorre a intimidação sistemática na rede mundial de computadores, quando são usados os instrumentos que lhe são próprios para depreciar, incitar a violência, adulterar fotos e dados pessoais com o intuito de criar meios de constrangimento psicossocial.

A Constituição Federal traz no artigo 5, Inciso X, que "são invioláveis a intimidade, a vida privada, a honra e a imagem das pessoas, assegurado o direito a indenização pelo dano material ou moral decorrente de sua violação"; portanto ninguém tem o direito de expor ou depreciar a imagem de outrem.

No campus pesquisado, 10 estudantes participantes da pesquisa relataram que foram expostos, envergonhados ou depreciados através das redes sociais. Em nenhum relato dos estudantes foi apontada a forma como ocorreu tal condição, porém é algo que está bem presente nas relações que vivenciam hoje, de acesso total e irrestrito às redes sociais e à internet.

Nas nove formas em que o bullying se desdobra e a violência demonstra sua face, percebe-se que a escola pesquisada ainda tem muito a avançar, porém, conforme relato das próprias profissionais, os atendimentos são realizados, os pais são chamados, ações pontuais são feitas. Não existe um protocolo padrão de atendimento a situações de bullying, pois, segundo a Profissional 1, os casos são conversados e analisados individualmente; conforme o relato da profissional, todos têm consciência da responsabilidade da escola para prevenir e combater essa prática:

legalmente falando eu creio que já exista o suficiente, pois temos uma Lei Federal que fala da intimidação sistemática, eu acho que toda escola já é munida de informações como está inscrita em seus próprios documentos que traz a sua missão, a sua missão social, sua função, sua meta, os direitos, os deveres e as obrigações... precisa haver formação para os professores, pois o problema não está especificamente no que está escrito, mas principalmente pelo discurso dos profissionais que aí sim a gente pode mexer, tem professor que entra em sala de aula falando contra as cotas que escola caiu a qualidade depois que entrou alunos através de cotas automaticamente, este é um discurso que promove a desigualdade entre os alunos porque se o professor usa esse discurso e teve essa fala isso não é bullying pois se o professor disse que o aluno cotista é burro não é bullying por que quem disse isso foi o professor, o professor e cientista o professor é doutor... (Entrevista Profissional 1, 2018). 
Diante de todos os fatos narrados é interessante debatermos a responsabilidade da escola frente a toda a problemática do bullying, já que, após a sanção da Lei n 13.663 , de 14 de maio de 2018, esta altera o artigo 12 da Lei no 9.394, de 1996 (Lei de Diretrizes e Bases da Educação Nacional). A lei inclui a responsabilidade da escola para promoção de medidas de combate ao bullying, que visa prevenir e combater todos os tipos de violência a partir da promoção da cultura da paz na escola. O trecho do texto acrescenta os incisos IX e X,

\section{Art. 12.}

IX - promover medidas de conscientização, de prevenção e de combate a todos os tipos de violência, especialmente a intimidação sistemática (bullying), no âmbito das escolas;

$\mathrm{X}$ - estabelecer ações destinadas a promover a cultura de paz nas escolas." (NR)

(BRASIL, Lei no 13.663, de 14 de maio de 2018).

Os estudantes já sinalizavam a importância de resolver a questão com ações institucionais, como segue em alguns relatos:

Trazer esse assunto pra escola, falar sobre isso para que as pessoas que fazem bullying entender que isso é sério, e pode machucar muito uma pessoa, mesmo que tenha feito ou falado alguma coisa só por brincadeira. (Estudante, 17 anos, Meio Ambiente).

Discutir abertamente com palestras/ou por meio de professores sobre raça, ideologia de gênero, orientação sexual, saúde e etc. discutir abertamente com argumentos que não sejam PRECONCEITUOSOS e CONSERVADORES. (Estudante, 15 anos, Química).

Há um entendimento dos estudantes que está preconizado na Lei Antibullying, que a escola e seus profissionais devem estar aptos para o enfrentamento dessa problemática, a partir do reconhecimento de que a escola não pode ser omissa, negando a existência do bullying e da violência. Porém, os professores precisam ser capacitados para atuar em uma perspectiva de formação dos temas da diversidade cultural e as relações de tolerância e intolerância. Silva (2009) traz o conceito de tolerância como uma forma de "aguentar o outro. Neste sentido, cada um permanece no seu lugar sem interferir na vida do outro" (SILVA, 2009, p. 135). No entanto, a tolerância deve ser assumida como modo de vida, agregando valores, contribuindo para uma sociedade mais pacífica, sem a intenção de se livrar do incômodo da presença do outro.

Grande desafio para a escola, no que diz respeito à formação de seu corpo docente e de sua equipe técnica, pois não é apenas levar temas transversais que abarquem questões de Direitos Humanos, é necessário conhecimento sobre a história, as lutas, os contextos, sem senso comum e superficialidade, pois isso pode promover um movimento contrário em que, ao invés de promover aproximação, ocorre o afastamento. A profissional entrevistada narra episódio de uma tentativa de abordar temas de diversidade cultural de sem a devida preparação. 
Precisa ter atenção em tratar esses temas porque já tivemos aqui professores que tiveram a boa ideia de trazer esses debates para sala de aula e não conseguiu fechar este debate e criou todo um problema na escola, e depois dessa tentativa malsucedida, tivemos até alunos que saíram da escola desta mesma turma após esse trabalho com o professor porque passou a sofrer bullying dos demais colegas era uma coisa que teve uma boa intenção mas acabou sendo malsucedida. (Entrevista Profissional 2, 2018).

Fica evidente a necessidade de formação continuada para os professores sobre temas complexos da sociedade contemporânea, além de abarcar questões referentes à valorização do ser humano, da dignidade humana, valores, identidade e diversidade cultural, pensando na transversalidade desses temas e sua aplicabilidade em todas as áreas do conhecimento.

\begin{abstract}
Pensar em uma campanha revolucionária pois campanha para entregar folder isto já acontece eu acredito que toda a intenção é boa mas esta é uma ação que pode ter bons resultados mas acredito que uma coisa que seria bem efetiva é que todo o professor tivesse que tratar temas transversais dentro de sala de aula independente da matéria que ele trabalha que seja matemática cálculo, estatística, o que fosse esse professor vai ter que pegar uma vertente de uma causa de um problema social, racismo, homofobia, machismo, intolerância religiosa, inclusão... Um monte de tema e inserir na sua disciplina de alguma forma a gente precisa tratar esses temas nessas beiradas assim. (Entrevista Profissional 2, 2018).
\end{abstract}

Observando que alguns caminhos estão sendo trilhados, as redes tecidas, o contexto desvelado, porém, como é possível compreender e estabelecer melhorias em uma instituição de ensino em que seus contex tos e sujeitos mudam constantemente, considera-se que essa seja uma luta que não se esgota, que envolve formação docente para uma formação mais humana, na qual não se perde de vista a humanidade dos seres passantes no cotidiano escolar. Chalita (2008) fala da conexão entre os seres, que não são sozinhos e são interdependentes, por esse motivo não se pode perder a compaixão, pois se a perder, se perde "a capacidade de se incomodar com o sofrimento alheio - e os incomodados são capazes de mudar o mundo" (CHALITA, 2008, p. $15)$.

Nesse movimento de perceber que todos estão conectados, que um mal interfere no coletivo, é preciso considerar Certeau (2004), quando relata que continua havendo diferenças sociais, econômicas e históricas entre os praticantes. Nesta consideração entra o papel formativo da escola, em que, como o autor considera, toda cultura "se elabora nos termos de relações conflituais ou competitivas entre mais fortes e mais fracos, sem que nenhum espaço, pode instalar-se na certeza da neutralidade" (CERTEAU, 2004, p. 86).

Silva (2009) fala desse espaço (escolar) que não é neutro e que há relações entre sujeitos praticantes de saberesfazeres em diferentes espaçostempos. $\mathrm{O}$ autor considera a plenitude se 
sua formação, quando o ser humano concebe que é constituída a partir das "relações com a cultura, com os outros e com o ambiente". O autor ainda traz a concepção de que o "educando deve estar consciente de que a identidade de um povo e do próprio ser humano individualmente é construída de forma coletiva e constante. Que deve respeitar e valorizar os saberes contidos nas outras culturas". O que se considera como o papel mais fundamental da escola, como local de formação e transformação, seja formar o ser humano que tenha consciência "de que é possível aprender e trocar saberes ou conhecimentos com outros grupos. Essa troca não tem mão única, isto é, um povo que recebe, aprende e outro que ensina e traz o conhecimento" (SILVA, 2009, p. 133).

\section{CONSIDERAÇões FinaIS}

Debater a temática bullying, violência e violação de direitos humanos, em que uma pesquisa da área de ensino, parte da concepção de que é uma temática complexa e que está ligada ao processo de ensino e aprendizagem. Buscou-se perceber como a temática da pesquisa estava presente nas relações cotidianas dos estudantes de Ensino Médio do IFMT Campus Cuiabá - Bela Vista. Nesse sentido, considera-se que a presente pesquisa apresentou um espaço escolar em que o bullying está presente e tem assumido características que se podem nomear como outros tipos de violência, como racismo, preconceito, homofobia e discriminação. Pautando-se por marcadores sociais específicos, que geram as diferenças e constituem a identidade dos estudantes, que podem ser determinantes para que ocorra atitudes agressivas nas relações escolares.

A necessidade de se desenvolver estratégias contra possíveis indisciplinas e violências nos estabelecimentos escolares vem ganhando legitimidade, por meio de táticas que tenham como instrumento a prática do diálogo, o reconhecimento da diversidade, o estabelecimento de relações interpessoais baseadas na cooperação e na solidariedade, e a diminuição da sensação de insegurança e de vulnerabilidade no cotidiano vivido e praticado pelos sujeitos da escola. Considera-se aqui fundamental a inclusão da educação em direitos humanos como uma estratégia de enfrentamento à problemática, partindo de debates e entendimento dos conceitos e características dos comportamentos de bullying, violências e violações de direitos contra a pessoa humana, como possibilidade de intervenção no cotidiano escolar, que é importante que parta da atuação dos próprios estudantes como atores principais na busca por soluções de seus problemas reais. 


\section{REFERÊNCIAS}

ABRAMOVAY, Miriam. Cotidiano nas escolas: entre violências. Brasília: UNESCO, 2006.

ABRAMOVAY, Miriam. et al. Violências nas escolas. Brasília: UNESCO Brasil, REDE PITÁGORAS, Coordenação DST/AIDS do Ministério da Saúde, Secretaria de Estado dos Direitos Humanos do Ministério da Justiça, CNPq, Instituto Ayrton Senna, UNAIDS, Banco Mundial, USAID, Fundação Ford, CONSED, UNDIME, 2002.

ANDRÉ, Marli (org.). O papel da pesquisa na formação e na prática dos professores. Campinas, São Paulo, SP: Papirus, 2001.

ARATANGY, Lídia. Documentário Educação: "Não me bullying também”. TV Novo empo, 2011.

ARENDT, Hannah. Homens em tempos sombrios. São Paulo: Companhia das Letras, 2008.

BRASIL. Comitê Nacional de Educação em Direitos Humanos. Plano Nacional de Educação em Direitos Humanos / Comitê Nacional de Educação em Direitos Humanos. - Brasília: Secretaria Especial dos Direitos Humanos, Ministério da Educação, Ministério da Justiça, UNESCO, 2007.

BRASIL. Presidência da República. Casa Civil. Subchefia para Assuntos Jurídicos. Lei no 13.185, de 6 de novembro de 2015. Institui o Programa de Combate à Intimidação Sistemática (Bullying). Brasília: DOU, 9.11.2015. Disponível em: <http://www.planalto.gov.br/ccivil_03/_Ato20152018/2015/Lei/L13185.htm>. Acesso em: 02 set. 2018.

BRASIL. Presidência da República. Casa Civil. Subchefia para Assuntos Jurídicos. Lei no 13.663, de 14 de maio de 2018. Altera o art. 12 da Lei $\mathrm{n}^{\circ}$ 9.394, de 20 de dezembro de 1996, para incluir a promoção de medidas de conscientização, de prevenção e de combate a todos os tipos de violência e a promoção da cultura de paz entre as incumbências dos estabelecimentos de ensino. Brasília: DOU, 15.5.2018.

BULLYING - Casos de bullying em escolas brasileiras. Disponível em:> http://g1.globo.com/sp/ribeirao-preto-franca/noticia/2015/05/pesquisa-aponta-que-20-dos-alunosja-praticaram-bullying-contra-colegas.html. Acesso em: 01 de mai. 2020.

CERTEAU, Michel de. A invenção do cotidiano 1: as artes de fazer. 10. ed. Petrópolis: Vozes, 2004.

CHALITA, Gabriel. Pedagogia da amizade - bullying: o sofrimento das vítimas e dos agressores. São Paulo: Gente, 2008.

FELIZARDO, Ribeiro Aloma. Bullying Escolar: prevenção, intervenção e resolução com princípios da justiça restaurativa. Curitiba: Intersaberes, 2017.

FANTE, Cléo. Fenômeno Bullying: como prevenir a violência nas escolas e educar para a paz. 2. ed. Campinas: Verus, 2005.

FERRAÇO, Carlos Eduardo. Pesquisa com o cotidiano. Revista Educação e Sociedade, Campinas, v. 28, n. 98, p. 73-95, jan./abr. 2007.

FERRAÇO, Carlos Eduardo, et al. Aprendizagens cotidianas com a pesquisa: novas reflexões em pesquisa nos/dos/com os cotidianos das escolas. Petrópolis: DP et Alii, 2008. 
FERRARI, Marcio. Michel Foucault: Um crítico da instituição escolar. Nova Escola. Disponível em: $<$ http://revistaescola.abril.com.br/formação/critico-instituicao-escolar-423110.shtml?page=2>. Acesso em: 24 de mar. 2020.

IFMT. Instituto Federal de Educação, Ciência e Tecnologia de Mato Grosso. Perguntas frequentes. 2018. Disponível em: <http://processoseletivo.ifmt.edu.br/conteudo/pagina/faq/>. Acesso em: 03 nov. 2018.

IFMT. Instituto Federal de Educação, Ciência e Tecnologia de Mato Grosso. Plano de Desenvolvimento Institucional (PDI), 2014. Cuiabá: IFMT, 2014.

IFMT. Instituto Federal de Educação, Ciência e Tecnologia de Mato Grosso. Regimento disciplinar discente. Resolução nº 115 de 13/09/16. Cuiabá: IFMT, 2016.

GIFFIN, Karen. Violência de Gênero, Sexualidade e Saúde. Cad. Saúde Pública, Rio de Janeiro, v. 10 (suplemento 1), p. 146-155, 1994.

LOPES, Alice Casimiro; MACEDO, Elizabeth. Teorias de Currículo. São Paulo: Cortez, 2011. $280 \mathrm{p}$.

MEC. Programa de Educação em Direitos humanos. Disponível em: http://portal.mec.gov.br/programa-educacao-em-direitos-humanos. Acesso em 21 de agosto de 2020.

MORIN, Edgar. Os sete saberes necessários à educação do futuro. São Paulo: Cortez, 2000.

MOTA, Raquel Martins Fernnandes et al. Pesquisa qualitativa em Educação: estudos transdisciplinares do Grupo de Pesquisa Humanidades e Sociedade Contemporânea do IFMT (GPHSC-IFMT). Indagatio Didactica, vol. 9 (3), novembro, 2017. ISSN: 1647-3582. https://proa.ua.pt/index.php/id/issue/view/92

OLIVEIRA, Inês Barbosa de; ALVES, Nilda (orgs.). Pesquisa nos/dos/com os cotidianos das escolas - sobre redes de saberes. Petrópolis: DP et Alii, 2008.

PEREIRA, Graziela Raupp; VARELA, Cristina Monteggia; SILVEIRA, Guilherme Pereira. O fenômeno do bullying homofóbico nas instituições de ensino: o direito à igualdade sexual e o princípio da dignidade da pessoa humana. Revista Ibero-Americana de Estudos em Educação, v. 10, n. esp., p. 1489-1596, 2015.

QUIJANO, Aníbal. Colonialidade do Poder, Eurocentrismo e América Latina. In: Colonialidade do Saber: eurocentrismo e ciências sociais. Perspectivas latinoamericanas. Edgardo Lander (org). ColecíonSurSur, CLACSO, Ciudad autônoma de Buenos Aires, Argentina. 2005.

SILVA, Ana Beatriz B. Bullying: mentes perigosas na escola. Rio de Janeiro: Objetiva, 2010.

SILVA, Clemildo Anacleto da. Educação, tolerância e direitos humanos: a importância do ensino de valores na escola. Porto Alegre: Sulina, 2009.

SILVA, Vanessa, Costa, Gonçalves. Violência escolar, bullying e violação de direitos humanos no cotidiano escolar. Cuiabá,

Recebido em: 30 de junho de 2020.

Aprovado em: 29 de agosto de 2020. 